\title{
Left ventricular volume reduction surgery for heart failure: A physiologic perspective
}

John H. Artrip, MDa

Mehmet C. Oz, MD

Daniel Burkhoff, MD, $\mathrm{PhD}^{\mathrm{b}}$

From the Department of Surgery, ${ }^{\mathrm{a}}$ Division of Cardiothoracic Surgery, Department of Medicine, ${ }^{\mathrm{b}}$ and Division of Circulatory Physiology, College of Physicians and Surgeons, Columbia University, New York, NY.

Received for publication Nov 28, 2000; revisions requested Feb 16, 2001; revisions received March 7, 2001; accepted for publication March 29, 2001

Address for reprints: Daniel Burkhoff, MD $\mathrm{PhD}$, Department of Medicine, Division of Circulatory Physiology, College of Physicians and Surgeons, Black Building 812, 650 W 168th St, New York, NY 10032 (E-mail: db59@columbia.edu).

J Thorac Cardiovasc Surg 2001;122:775-82

Copyright (c) 2001 by The American Association for Thoracic Surgery

$0022-5223 / 2001 \$ 35.00+0 \quad \mathbf{1 2 / 1 / 1 1 6 2 0 8}$

doi:10.1067/mtc. 2001.116208
Background: Ventricular volume reduction surgery for idiopathic cardiomyopathy fails to improve cardiac output and is associated with a high incidence of recurrent heart failure. Volume reduction surgery achieved by removing akinetic or dyskinetic myocardium after myocardial infarction appears to be associated with better outcomes. The reasons for the differences in outcomes are not clear.

Methods and Results: The hemodynamic effect of the major forms of volume reduction surgery were predicted by using a composite model of the left ventricle in which $20 \%$ of the myocardium was given properties of either weak but contracting muscle, an akinetic scar, or a dyskinetic scar (aneurysm). The end-systolic and end-diastolic pressure-volume relationships were determined numerically for each simulated operation. Any volume reduction procedure reduced chamber size, shifting end-systolic and end-diastolic pressure-volume relationships leftward. With resection of weak but contracting muscle, the leftward shift was greater for the enddiastolic than for the end-systolic pressure-volume relationship. Conversely, with resection of dyskinetic scar, the leftward shift was greater for end-systolic than for end-diastolic pressure-volume relationships. In contrast, resection of stiff scar shifted the 2 relationships equally. The effect on overall pump function was indexed by the relationship between total ventricular mechanical work and end-diastolic pressure. There was a beneficial effect on this relationship of resecting dyskinetic tissue, an equivocal effect of akinetic scar resection, and a negative effect of removing contracting myocardium.

Conclusions: The effect of volume reduction surgery on overall ventricular pumping characteristics is determined by the differential effects on end-systolic and enddiastolic properties, which in turn are determined by the material properties of the region being removed.

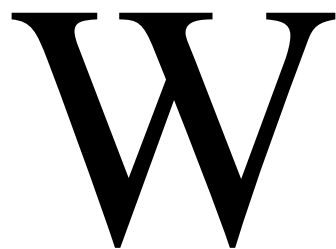

ith the large number of patients having advanced heart failure and the small number of patients for whom heart transplantation will be available, interest in left ventricular reduction surgery has intensified in recent years. Such procedures are performed on poorly functioning dilated hearts and involve the removal of a portion of the ventricular wall to decrease chamber radius. The Batista procedure, ${ }^{1}$ the endoventricular circular patch plasty described by Dor and colleagues, ${ }^{2,3}$ and various forms of ventricular aneurysmorrhaphy ${ }^{4-6}$ represent the major variations of this therapy, not only with respect to surgical technique but also importantly with respect to the patient population potentially eligible for this form of therapy.

Laplace's law, the relationship between chamber diameter and wall stress, is cited as one of the physical principles underlying the potential benefits of volume reduction. Although it is true that a reduction of chamber radius will reduce wall stress for a given pressure, it is not obvious from this explanation alone that volume reduction will result in an increased pumping capacity of the heart. Recently, a com- 

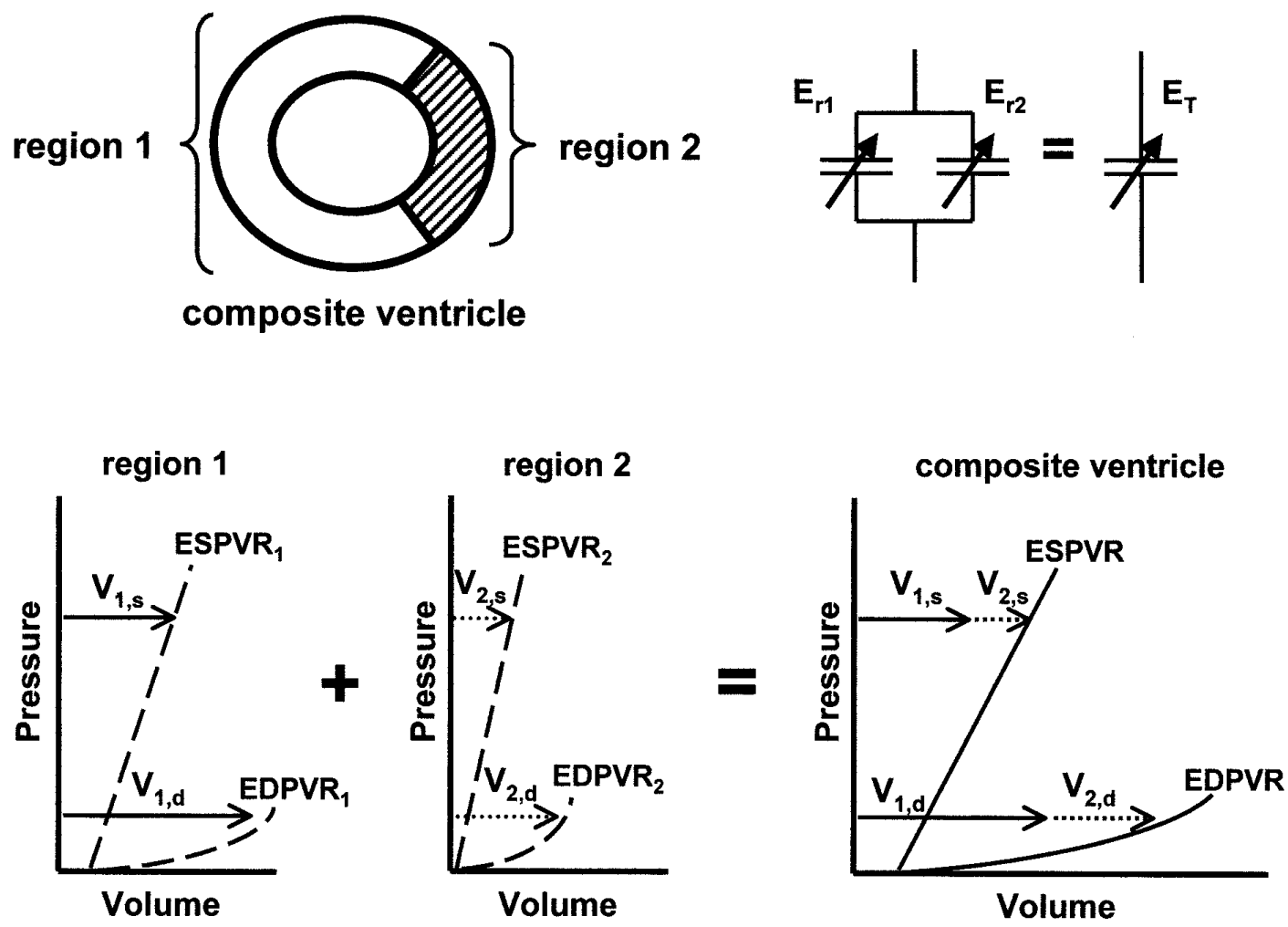

Figure 1. Top left, Schematic representation of the composite left ventricle, consisting of 2 distinct regions of myocardium with different contractile properties. Top right, Regional myocardial elastances $\left(E_{r}\right)$ can be added together to determine the total ventricular elastance $\left(E_{T}\right): 1 / E_{r, 1}+1 / E_{r, 2}=1 / E_{T}$. Bottom, Illustration of additive properties of regional ESPVRs and EDPVRs to give a composite ventricle. At a given pressure, the volume of the ESPVR and EDPVR for each region add to generate the composite ESPVR and EDPVR.

prehensive analysis based upon physiologic principles was used to predict the effects of volume reduction surgery in the setting of idiopathic dilated cardiomyopathy (ie, the Batista operation). ${ }^{7}$ The analysis revealed a potential limitation of this procedure: removing functioning (even weakened) myocardium, although reducing systolic wall stress and improving ejection fraction, is associated with a deleterious effect on diastolic compliance that counteracts the beneficial effects on systolic wall stress. This may actually reduce net ventricular pumping capacity (indexed by the Frank-Starling relationship).

Despite tremendous initial enthusiasm and numerous anecdotal reports of good outcome, results of recent clinical studies now suggest that this procedure is associated with a high combined rate of mortality, requirement for transplantation or left ventricular assist device implantation, or persistent symptoms of severe heart failure. ${ }^{8}$ As enthusiasm for the Batista procedure wanes, interest in volume reduction through endoventricular patch plasty or aneurysmorrhaphy for selected patients after myocardial infarction is increasing on the basis of more positive experiences reported in the literature. ${ }^{9-12}$ These procedures differ conceptually from the
Batista procedure in that instead of removing functioning myocardium, ventricular volume reduction is achieved through removing (or functionally excluding) stiff regions of akinetic scar or relatively more compliant dyskinetic scar. ${ }^{3-6}$ Although surgical treatment of dyskinetic scar (aneurysm) is considered accepted therapy for heart failure, there is less of a consensus regarding volume reduction through exclusion of akinetic wall segments and the physiologic consequences of such procedures. Accordingly, we used analytic techniques to determine the hemodynamic effects of volume reduction achieved through removal of akinetic scar and compared these effects with those achieved through removal of contracting myocardium (the Batista procedure) or removal of dyskinetic scar.

\section{Methods}

\section{Theoretic Considerations}

Mechanical pump properties of the normal left ventricle can be characterized by end-systolic and end-diastolic pressure-volume relationships (ESPVR and EDPVR, respectively), ${ }^{13}$ each of which quantify the volume-capacitance of the chamber in the respective phase of the cardiac cycle. The ESPVR is relatively load indepen- 

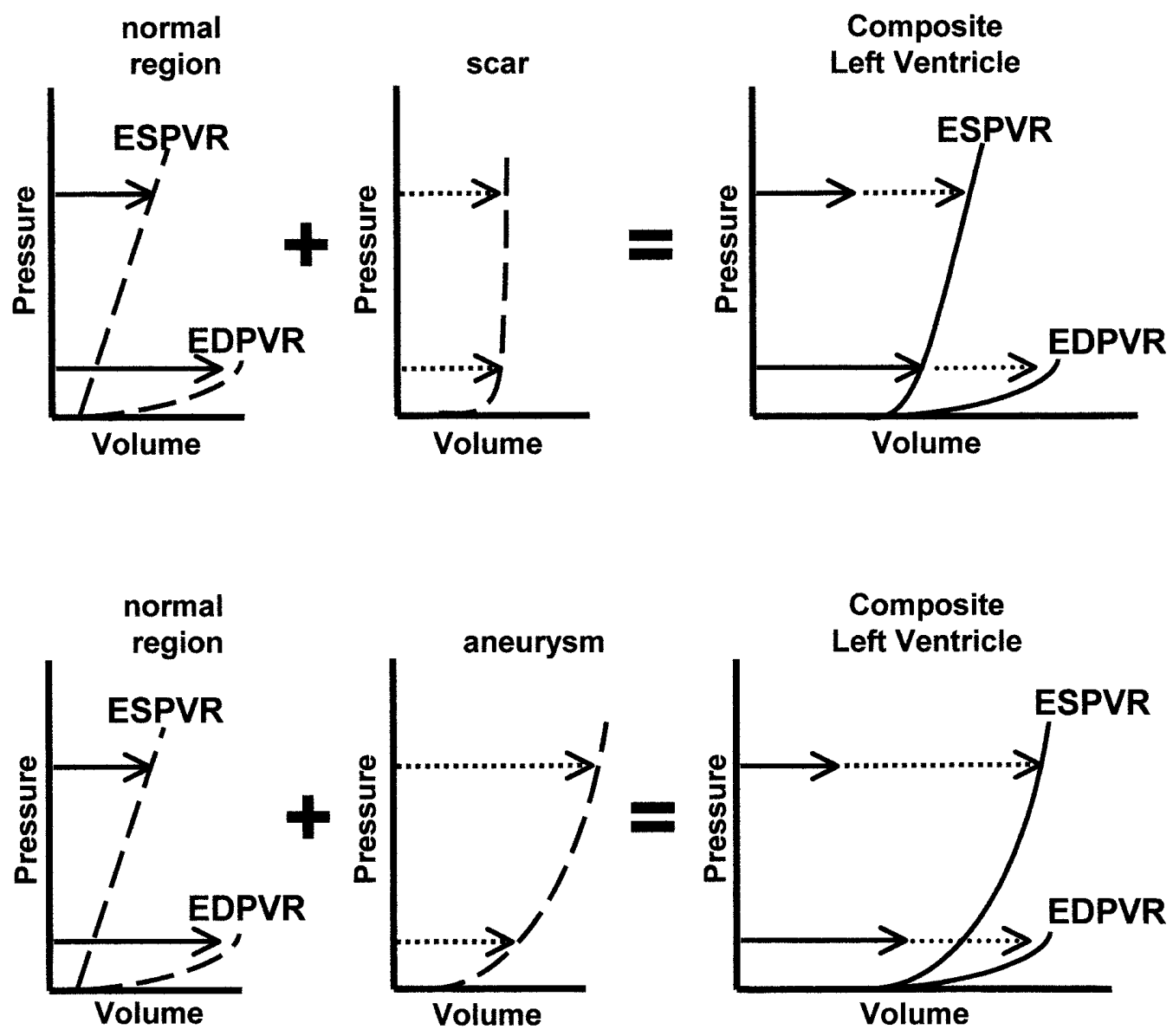

Figure 2. Illustration of additive properties of regional ESPVRs and EDPVRs to give a composite ventricle with a stiff akinetic scar (top) or compliant dyskinetic aneurysm (bottom).

dent and linear, with a slope (the end-systolic elastance $\left[\mathrm{E}_{\mathrm{es}}\right]$ ) that varies with myocardial contractility and a volume axis intercept $\left(\mathrm{V}_{\mathrm{o}}\right)$ that varies with chamber size:

$$
\mathrm{P}_{\mathrm{es}}=\mathrm{E}_{\mathrm{es}}\left(\mathrm{V}_{\mathrm{es}}-\mathrm{V}_{\mathrm{o}}\right)
$$

where $\mathrm{P}_{\mathrm{es}}$ and $\mathrm{V}_{\mathrm{es}}$ are end-systolic pressure and volume, respectively. The EDPVR is exponential and commonly quantified by a stiffness coefficient $(\mathrm{K})$ and a scaling factor $(\mathrm{A})$ that vary with passive myocardial properties:

$$
\mathrm{P}_{\text {ed }}=\mathrm{A}\left(\mathrm{e}^{\mathrm{K}(\mathrm{Ved}-\mathrm{Vo})}-1\right)
$$

where $\mathrm{P}_{\text {ed }}$ and $\mathrm{V}_{\text {ed }}$ are end-diastolic pressure (EDP) and end-diastolic volume, respectively. During a contraction, ventricular mechanical properties cycle between the end-diastolic and endsystolic properties described by these equations, which lead to the notion of the heart as a time-varying elastance that can be represented symbolically as a time-varying capacitive element. ${ }^{13}$

In the event that myocardial properties differ from one region to the next, global ventricular properties can be represented by the interaction between two capacitive elements, each with its own pressure-volume characteristics, ${ }^{14}$ as shown in the top panel of
Figure 1. The effective pressure-volume relations of each region will depend on the time-varying material properties of that region and the proportion of total ventricular mass having those properties. Because at each instant of the cardiac cycle both portions of the chamber are exposed to the same pressure, the pressure-volume properties of the composite ventricle are determined by adding volumes at each pressure, as shown for the ESPVRs and EDPVRs in the bottom panel of Figure 1.

After a transmural myocardial infarction, the material properties of the affected region can be varied. In some instances the infarcted myocardium can be stiff, resulting in an akinetic region with a steep pressure-volume relationship (Figure 2, top panel). Alternatively, the infarcted region can be compliant, resulting in a dyskinetic scar with a shallow pressure-volume relationship (Figure 2, bottom panel). In either case, material properties in the affected area are fixed in time because there are no remaining contractile elements in these extremes. The affected region interacts with the remote area of contracting myocardium, such that the contractile property of the composite ventricle is the sum of the 2 regions. The pressure-volume relations in systole and diastole of the composite ventricles are shown on the right side of Figure 2 and reveal the net pump properties of the heart. 

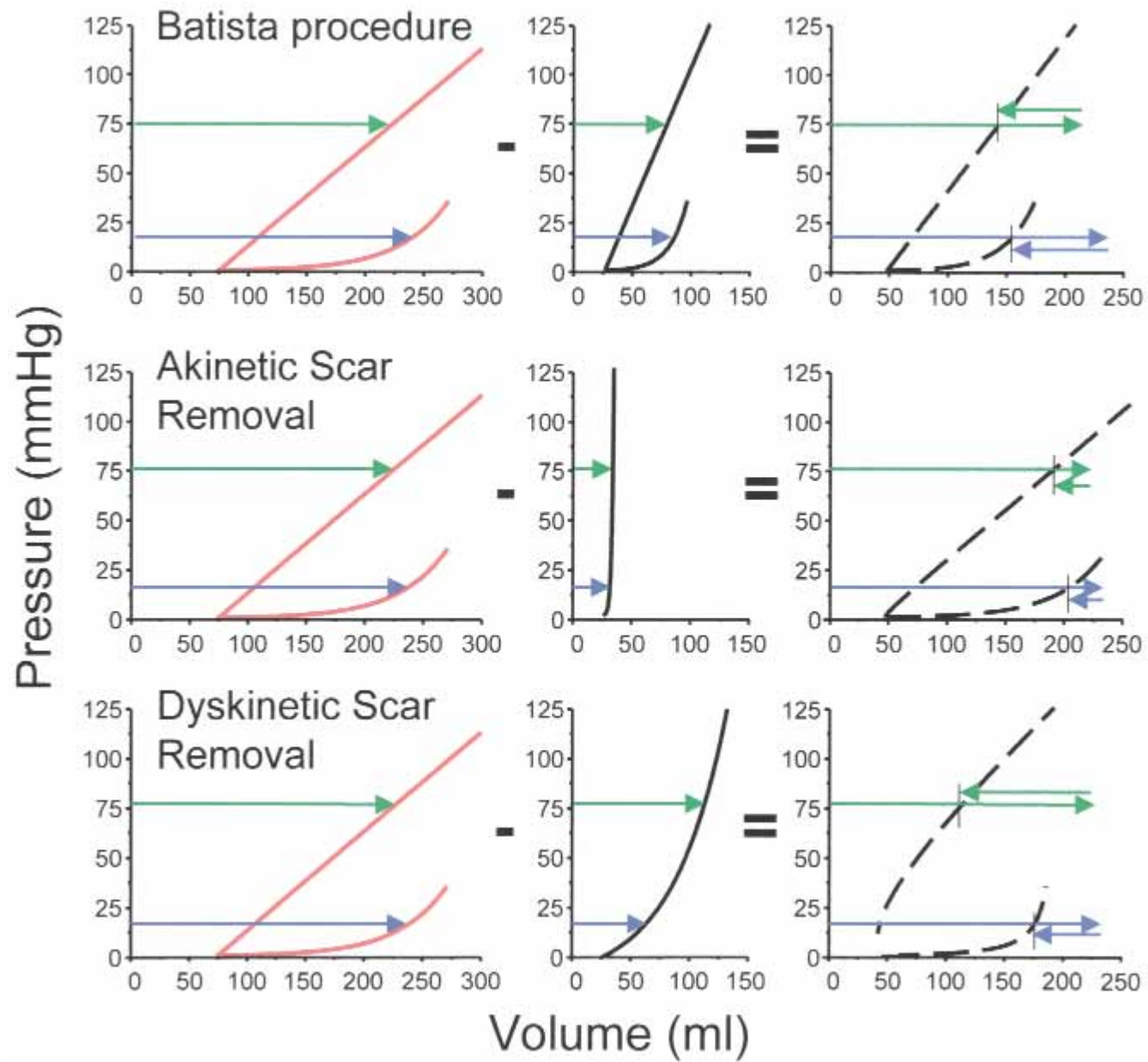

Figure 3. Pressure-volume tracings taken from a simulated composite ventricle after a Batista procedure (top), removal of an akinetic segment (middle), or removal of a dyskinetic segment (bottom). Green arrows indicate systolic properties in the composite and removed sections; blue arrows indicate diastolic properties. The net effect of the volume reduction depends on differential shifts on the ESPVR and EDPVRs, which in turn depend on the pressure-volume characteristics at different times (systole vs diastole) and pressure levels of the segment being resected.

Removal of a region can be similarly modeled by subtracting regional pressure-volume relations of the region to be removed from the original global pressure-volume relationships to illustrate the effects of ventricular reduction surgery. By varying properties of the region to be removed, the effect of removing contracting (Batista procedure), akinetic, or dyskinetic segments of ventricular wall from a working ventricle can be predicted.

\section{Modeling of the Left Ventricle and Regional Wall Properties}

To illustrate the 3 major forms of ventricular reduction surgery, $20 \%$ of the left ventricle was given properties of either weak but contracting muscle, an akinetic scar, or a dyskinetic scar. The remainder of the heart was composed of contracting muscle, and the composite properties of the ventricles (in terms of ESPVR and EDPVR) for the starting heart failure state were the same for all 3 conditions. The properties of the akinetic scar and dyskinetic scar were each described by a time-invariant pressure-volume relationship with the equation for the EDPVR and similar parameters, except for a stiffness coefficient set to 10 times the normal value for the akinetic scar and one half the normal value for the dyskinetic scar.

\section{Overall Pump Function}

Removal of a region of myocardium may have different effects on systolic and diastolic properties, making it difficult to understand the effect on overall pump function. To assess effects on overall pump function, we examined the relationship between the maximum total work the heart could perform as a function of EDP. Maximum total work at any EDP was quantified by the maximum pressure-volume area $\left(\mathrm{PVA}_{\max }\right)$, which is the area confined within the ESPVR and EDPVR between $\mathrm{V}_{\mathrm{o}}$ and the end-diastolic volume at the EDP of interest. 
TABLE 1. Parameter values for the ESPVR and EDPVR

\begin{tabular}{|c|c|c|c|c|}
\hline & \multicolumn{2}{|c|}{ ESPVR $^{*}$} & \multicolumn{2}{|c|}{ EDPVRT } \\
\hline & $\mathrm{E}_{\mathrm{es}}(\mathrm{mm} \mathrm{Hg} / \mathrm{mL})$ & $V_{0}(m L)$ & $A(\mathrm{~mm} \mathrm{Hg})$ & $\mathrm{K}\left(\mathrm{mL}^{-1}\right)$ \\
\hline Heart failure & 0.50 & 75 & 0.32 & 0.024 \\
\hline Batista procedure & 0.77 & 48.2 & 0.32 & 0.037 \\
\hline Akinetic scar removal & 0.51 & 48.2 & 0.32 & 0.025 \\
\hline Dyskinetic scar removal & 0.79 & 48.2 & 0.32 & 0.043 \\
\hline
\end{tabular}

*The parameter values for the ESPVR were determined by first normalizing the numeric data so that $\mathrm{V}_{0}$ values were approximately equal to the resting volume at baseline or after a $20 \%$ surface area reduction. The data were then fit to the curve $Y=E_{e s}\left(V-V_{0}\right)$, to determine $E_{e s}$ values.

tThe parameter values for the EDPVR were determined by fitting the data to the curve $\mathrm{Y}=\mathrm{A}\left(\mathrm{e}^{\mathrm{K}(\mathrm{X}-\mathrm{es})}-1\right)$, where the value of $A$ was set to 0.32 and the value of $C$ was set to the value of $\mathrm{V}_{0}$.

\section{Numeric Calculations}

All numeric calculations were performed with Microsoft Excel.

\section{Results \\ Effect of Ventricular Resections on ESPVR and EDPVR}

The ESPVRs and EDPVRs simulating myopathic hearts are illustrated in the red tracings of Figure 3. A heart with idiopathic cardiomyopathy is shown in which all regions of the heart have the same weak contractile properties (Figure 3, top). A heart with a stiff infarct is shown in the middle of Figure 3, and a heart with a compliant infarct is shown at the bottom of Figure 3. In creating this simulation, the starting global properties of the hearts (ie, the ESPVRs and EDPVRs) were the same for all 3 scenarios, so that the effects of removing the variably affected region could be clearly illustrated.

When weak but contracting muscle is removed (Batista procedure), the EDPVR is shifted by an amount determined by the passive myocardial properties (blue arrows), whereas the ESPVR is shifted by an amount determined by the stiffer systolic properties (green arrows). As a result, the EDPVR is shifted more to the left than is the ESPVR. This reduces the area between the ESPVR and EDPVR compared with the original heart, which will have detrimental effects on overall pump properties.

When stiff, noncontracting myocardium is removed (or excluded), the EDPVR and ESPVR shift by similar amounts at all pressures (blue and green arrows). Thus, the area between the ESPVR and EDPVR is relatively unchanged from the original state.

When compliant dyskinetic myocardium is removed, the effect on the pressure-volume relationship is highly pressure dependent. For the EDPVR, which resides at lower pressures, there is less of a leftward shift (blue arrows) than for the ESPVR at higher pressures (green arrows). As a result, the curvilinearity of this relationship is affected, and there is a significant increase in the area between the ESPVR and EDPVR.
The parameter values for the ESPVRs and EDPVRs obtained from least-squared fitting of the curves in Figure 3 are summarized in Table 1. Removal or exclusion of any segment of ventricular wall (regardless of function) resulted in a leftward shift of the ESPVR (ie, decrease in the $\mathrm{V}_{\mathrm{o}}$ value), but changes in the slope (ie, increase in the $E_{e s}$ value) depended on the type of muscle being resected. The $\mathrm{E}_{\mathrm{es}}$ values obtained were greatest after removal of dyskinetic scar and increased after removal of contracting myocardium but were nearly identical to the baseline heart failure state after removal of akinetic scar. Ventricular diastolic stiffness (indexed by the $\mathrm{K}$ values, Table 1) was also increased after removal of dyskinetic scar or contracting myocardium but was approximately unchanged after removal of akinetic myocardium.

\section{Effect of Ventricular Resections on Ventricular Work}

The relationship between $\mathrm{PVA}_{\max }$ (an index of total ventricular work) and EDP provides a load-independent assessment of global ventricular pump function. These plots, illustrated in Figure 4, were also determined for the heart-failure ventricle and for each ventricle after the 3 simulated surgical procedures. As suggested above by the description of differential shifts in ESPVRs and EDPVRs, removal of contracting myocardium (Batista procedure) shifts the curve downward from baseline (solid red line vs solid black line), whereas removal of akinetic scar does not significantly change the curve from baseline (solid red line vs dashed black line). However, removal of dyskinetic scar shifts the curve upward from baseline (solid red line vs dotted black line), suggesting improved overall pumping capacity.

\section{Discussion}

With the growing clinical experience in performing left ventricular volume reduction surgery, clinical and basic researchers are now better equipped to critically evaluate the potential benefits and limitations of this class of procedures. Despite the initial anecdotal reports of clinical success and 


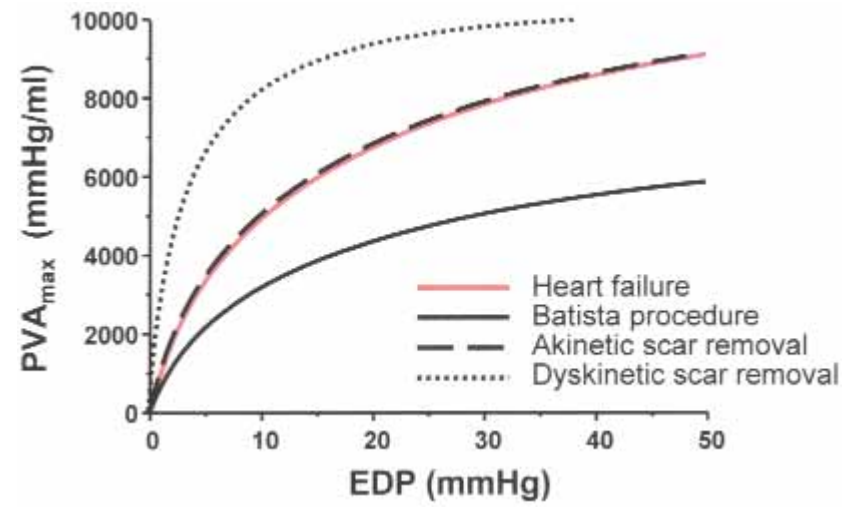

Figure 4. Illustration of the Starling-work relations (PVA $_{\max }$ vs EDP) for a Batista procedure, for the case of removing an akinetic segment, and for the case of removing a dyskinetic segment, as indicated in the inset. Overall, the Batista procedure reduces, resection of a dyskinetic segment increases, and resection of an akinetic section has little effect on overall pump function.

early enthusiasm for this Batista procedure, ${ }^{1}$ recent larger clinical studies suggest that this procedure does not improve cardiac output and can be associated with a high incidence of recurrent heart failure. ${ }^{8,15,16}$ Left ventricular volume reduction, however, may prove beneficial in selected patient populations. Volume reduction achieved through excision or exclusion of a stiff akinetic scar or a relatively compliant dyskinetic scar has been performed with more success in patients after myocardial infarction. ${ }^{9,12}$

The failure of volume reduction surgery to improve cardiac output or provide other detectable hemodynamic benefits in the setting of idiopathic dilated cardiomyopathy was predicted by a physiologic model on the basis of modern theories of ventricular physiology ${ }^{7}$ before clinical data were available. Results from that prior study suggested that removing functioning myocardium reduces peak wall stress-pressure relationships but at the expense of increased diastolic wall stiffness, with a net reduction in overall ventricular pump function. The major hemodynamic predictions of this analysis were confirmed in later clinical studies. ${ }^{15,17}$ This demonstrated the potential value of the present analytic approach to understanding the hemodynamic effects of operations to remodel the failing heart.

The present study aimed to similarly explore the hemodynamic effects of removing akinetic or dyskinetic scars compared with those of the Batista procedure. It was shown that volume reduction decreased chamber size with leftward shifts of both the EDPVR and ESPVR. However, the relative shifts of these relationships varied depending on the material properties of the resected myocardium. Removal of dyskinetic scar shifted the ESPVR more leftward than the EDPVR, whereas removal of contracting myocardium had the opposite effect. Removal of akinetic scar shifted the ESPVR and EDPVR equally. Perhaps less important, changes in the slopes of both the systolic and diastolic relations also depended on the properties of the resected myocardium. Removal of contracting myocardium or dyskinetic scar significantly increased $\mathrm{E}_{\mathrm{es}}$, whereas removal of an akinetic myocardial segment had little effect on this value. Removal of a dyskinetic scar or contracting myocardium resulted in significantly stiffer chambers, whereas removal of an akinetic myocardial segment had little effect on this relationship other than to shift it leftward.

In situations in which there are differential effects of a procedure on end-systolic and end-diastolic pressurevolume relationships, analysis of the net effect on global ventricular pump function can be complex. To address this issue directly, we examined the relationship between maximal possible mechanical work, indexed by $\mathrm{PVA}_{\max }$ and EDP. Unlike traditional Starling curves, which plot the relationship between preload and stroke volume or external stroke work, the $\mathrm{PVA}_{\max }$-EDP relationship provides an afterload-independent assessment of pump function and indexes the area between the end-diastolic pressure-volume and end-systolic pressure-volume relationships. The results demonstrated a beneficial effect of removing dyskinetic scar, an equivocal effect of removing akinetic myocardium, and a negative effect of removing contracting myocardium on overall ventricular pump function.

\section{Limitations}

Although this analysis provides insight into the acute effects of surgical procedures to remodel the failing heart under different circumstances, the results should not be extrapolated beyond what they model, namely, the acute effects on global ventricular pump function. Even in this regard, the approach oversimplifies a complex procedure, and several limitations should be acknowledged. First, this analysis does not account for the fact that in clinical practice the spectrum of ventricular properties encountered is heterogenous, and areas of weakened muscle and increased interstitial fibrosis and regions of frank akinetic and dyskinetic scars may all be present and interspersed. Such heterogeneity may contribute to nonuniform clinical responses observed with such surgical therapies. Even for the Batista procedure, there have been reports within the context of nonrandomized, nonblinded studies that some patients appeared to have benefited both in the acute ${ }^{15}$ and chronic ${ }^{16}$ settings. Second, the analysis does not address the changes in ventricular geometry that occur with volume reduction procedures; rather, with this pressure-volume approach, the influence of changes in chamber geometry on the transduction of wall stress to intraventricular pressure is ignored. These aspects, which could be important, are more readily dealt with by finite element analyses, such as the one per- 
formed by Ratcliff and colleagues, ${ }^{18}$ in analyzing the Batista procedure. It is noteworthy, however, that the fundamental predictions of this more complicated approach were consistent with those of the simpler pressure-volume approach used in our analysis. ${ }^{7}$ In addition, we have assumed that the properties of the noninfarcted myocardium and the myopathic muscle (for the case of the global cardiomyopathy simulation) are all the same. However, muscle properties and the degree of interstitial fibrosis may differ between idiopathic and ischemic cardiomyopathy and may even depend on the site of an infarct and on whether the scar is akinetic or dyskinetic. Despite such limitations, the present approach has been successfully used to quantitatively explain ventricular mechanics over a range of physiologic conditions, such as regional ischemia, ${ }^{14}$ altered activation sequence, ${ }^{19}$ and interventricular interactions ${ }^{20}$ in addition to the Batista procedure. ${ }^{7}$

Additionally, the failure of an operation to acutely improve ventricular pumping capacity does not necessarily equate with it being ineffective as a treatment for heart failure, and the results of the present analysis do not address potential long-term consequences of volume-reduction operations. As noted above, these operations are associated with ventricular shape changes (from spherical to the more normal elliptical shape) that, in addition to reduced radius of curvature, act to decrease wall stress. ${ }^{21}$ Reduced wall stress may result in regression of hypertrophy, improved myocyte function, and decreased expression and secretion of autocrine and paracrine substances produced by the myocardium in the face of increased mechanical stress (eg, natriuretic peptides and angiotensin II). ${ }^{22}$ However, if the original concept on which these types of surgical therapies are based (ie, to improve pump function) is abandoned, then the rationale for pursuing them becomes more theoretical. Indeed, if any such effects were present for the Batista procedure, they were not substantial enough to provide clinical benefits in a majority of patients. Additionally, the only published reports on this topic indicate that serum natriuretic peptide levels increase in a vast majority of patients who survived the Batista operation. ${ }^{23}$

\section{Summary}

It is not the intention of the present analysis to suggest or dispute the clinical application of any particular surgical procedure. The purpose is to reveal physiologic principles that can lead to greater understanding of how overall pump properties are affected, thus providing a foundation on which experiments, both clinical and preclinical, can be based. The principle revealed in the present study is the importance of understanding the differential effects on systolic and diastolic pump properties that may be created by removing material of different characteristics. Removal of contracting myocardium (Batista) affected diastolic proper- ties more than systolic properties, resulting in a net decrease in pump function. In contrast, removal of compliant, dyskinetic infarcted tissue more significantly affected systolic properties than diastolic properties, resulting in increased pump function. Finally, removal or exclusion of stiff, akinetic infarcted tissue equally affected systolic and diastolic properties, resulting in no significant change in pump function. It will be of great interest to follow the results of ongoing clinical trials of volume reduction surgery for patients with akinetic scars to see, despite the predictions of this analysis, whether and on what basis any clinical benefits are provided.

\section{References}

1. Batista RJ, Verde J, Nery P, Bocchino, Takeshita N, Bhayana JN, et al. Partial left ventriculectomy to treat end-stage heart disease. Ann Thorac Surg. 1997;64:634-8.

2. Dor V, Soab M, Coste P, Kornaszewska M, Montiglio F. Left ventricular aneurysm: a new surgical approach. J Thorac Cardiovasc Surg. 1989;7:11-9.

3. Dor V, Sabatier M, Montiglio F, Coste P, Di Donato M. Endoventricular patch reconstruction in large ischemic wall-motion abnormalities. J Card Surg. 1999;14:46-52.

4. Cooley DA, Collins HA, Morris GGC, Chapman DW. Ventricular aneurysm after myocardial infarction. Surgical excision with use of temporary cardiopulmonary bypass. JAMA. 1958;167:557-65.

5. Cooley DA, Frazier OH, Duncan JM, Reul GJ, Krajcer Z. Intracavitary repair of ventricular aneurysm and regional dyskinesia. Ann Surg. $1992 ; 215: 417-23$

6. Jatene AD. Left ventricular aneurysmectomy. Resection or reconstruction. J Thorac Cardiovasc Surg. 1985;89:321-31.

7. Dickstein ML, Spotnitz HM, Rose EA, Burkhoff D. Heart reduction surgery: an analysis of the impact on cardiac function. $J$ Thorac Cardiovasc Surg. 1997;113:1032-40.

8. Moreira LF, Stolf NA, Bocchi EA, Bacal F, Giorgi MC, Parga JR, et al. Partial left ventriculectomy with mitral valve preservation in the treatment of patients with dilated cardiomyopathy. J Thorac Cardiovasc Surg. 1998;115:800-7.

9. Faxon DP, Myers WO, McCabe CH, Davis KB, Schaff HV, Wilson JW, et al. The influence of surgery on the natural history of angiographically documented left ventricular aneurysm: the Coronary Artery Surgery Study. Circulation. 1986;74:110-8.

10. Kawachi K, Kitamura S, Kawata T, Morita R, Nishii T, Seki T, et al. Hemodynamic assessment during exercise after left ventricular aneurysmectomy. J Thorac Cardiovasc Surg. 1994;107:178-83.

11. Mickleborough LL, Maruyama H, Liu P, Mohamed S. Results of left ventricular aneurrysmectomy with a tailored scar excision and primary closure. J Thorac Cardiovasc Surg. 1994;107:690-8.

12. Dor V, Sabatier M, Di Donato M, Montiglio F, Toso A, Maioli M. Efficacy of endoventricular patchplasty in large post-infarction akinetic scar and severe left ventricular dysfunction: comparison with a series of large dyskinetic scars. J Thorac Cardiovasc Surg. 1998;116:50-9.

13. Suga H, Sagawa K. Instantaneous pressure-volume relationships and their ratio in the excised, supported canine left ventricle. Circ Res. 1974;35:117-26.

14. Sunagawa K, Maughan WL, Sagawa K. Effect of regional ischemia on the left ventricular end-systolic pressure-volume relationship of isolated canine hearts. Circ Res. 1983;52:170-8.

15. Gorscan J III, Feldman AM, Kormos RL, Mandarino WA, Demetris AJ, Batista RJV. Heterogeneous immediate effects of partial left ventriculectomy on cardiac performance. Circulation. 1998;97:839-42.

16. McCarthy JF, McCarthy PM, Starling RC, Smedira NG, Scalia GM, Wong J, et al. Partial left ventriculectomy and mitral valve repair for end-stage congestive heart failure. Eur J Cardiothorac Surg. $1998 ; 13: 337-43$ 
17. Schreuder JJ, Steendijk P, van der Veen FH, Alfieri O, van der NT, Lorusso R, et al. Acute and short-term effects of partial left ventriculectomy in dilated cardiomyopathy: assessment by pressure-volume loops. J Am Coll Cardiol. 2000;36:2104-14.

18. Ratcliffe MB, Hong J, Salahieh A, Ruch S, Wallace AW. The effect of ventricular volume reduction surgery in the dilated, poorly contractile left ventricle: a simple finite element analysis. $J$ Thorac Cardiovasc Surg. 1998;116:566-77.

19. Burkhoff D, Oikawa RY, Sagawa K. Influence of pacing site on canine left ventricular contraction. Am J Physiol. 1986;251:H428-35.

20. Maughan WL, Sunagawa K, Sagawa K. Ventricular systolic interde- pendence: volume elastance model in isolated canine hearts. Am J Physiol. 1987;253:H1381-90.

21. Green GR, Moon MR, DeAnda A, Daughters GT, Glasson JR, Miller DC. Effects of partial left ventriculectomy on left ventricular geometry and wall stress in excised porcine hearts. $J$ Heart Valve Dis. 1998;7:474-83.

22. Hunter JJ, Chein KR. Signaling pathways for cardiac hypertrophy and failure. N Engl J Med. 1999;341:1276-83.

23. Weston MW, Vijayangar R, Overton RM, Vesely DL. Prospective evaluation of the Batista procedure with circulating atrial natriuretic peptides. Int J Cardiol. 2000;74:145-52.

Access to The Journal of Thoracic and Cardiovascular Surgery Online is reserved for print subscribers!

Full-text access to The Journal of Thoracic and Cardiovascular Surgery Online is available for all print subscribers. To activate your individual online subscription, please visit The Journal of Thoracic and Cardiovascular Surgery Online, point your browser to http://www.mosby.com/jtcvs, follow the prompts to activate your online access, and follow the instructions. To activate your account, you will need your subscriber account number, which you can find on your mailing label (note: the number of digits in your subscriber account number varies from 6 to 10). See the example below in which the subscriber account number has been circled:

\section{Sample mailing label}

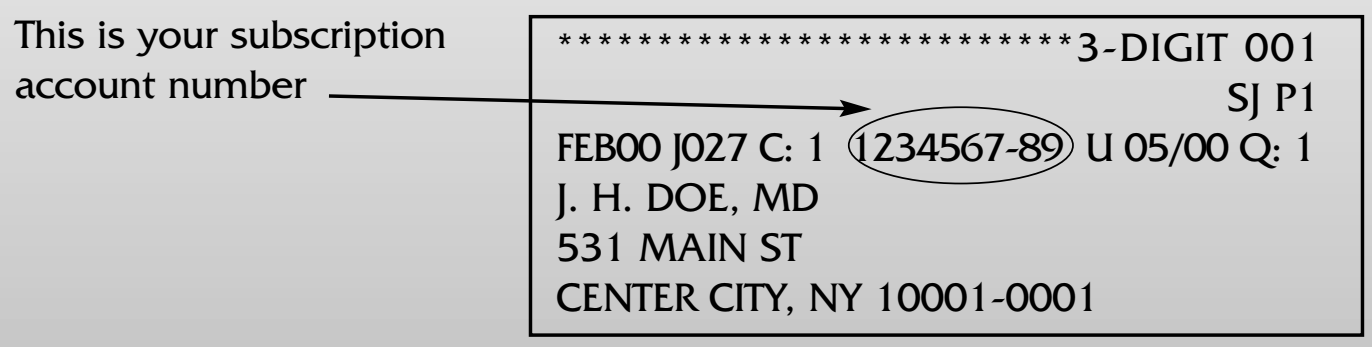

Personal subscriptions to The Journal of Thoracic and Cardiovascular Surgery Online are for individual use only and may not be transferred. Use of The Journal of Thoracic and Cardiovascular Surgery Online is subject to agreement to the terms and conditions as indicated online. 